\title{
A cultura da avaliação e da responsabilização nas reformas educacionais pós-1990
}

\author{
Givanildo da SILVA ${ }^{2}$ \\ Dayane Queiroz dos Santos CARVALHO
}

\begin{abstract}
Resumo
As práticas educativas no "chão" da escola são orientadas por meio das concepções postas nas políticas educacionais, designadas pelas reformas administrativas. O objetivo da pesquisa foi compreender o papel do Estado e das reformas educacionais na cultura de avaliação e de responsabilização na educação brasileira, tendo, como ponto de partida, a compreensão de que a educação pública é um campo complexo, dinâmico e arenoso. A metodologia esteve pautada em uma abordagem qualitativa na perspectiva da pesquisa exploratória em uma escola pública municipal de Maceió. Os principais resultados apontaram que as reformas educacionais instauradas pós-1990, que intensificaram a cultura de avaliação e de responsabilização, modificaram a organização da escola, atribuindo princípios mercadológicos na prática educacional, por meio da administração pública gerencial.
\end{abstract}

Palavras-chave: Cultura de avaliação. Responsabilização. Políticas Educacionais.

\footnotetext{
${ }^{1} \mathrm{O}$ artigo é resultado da pesquisa de iniciação cientifica intitulada “as avaliações em larga escala na educação pública: a visão de professores e de gestores dos anos iniciais em Maceió”, financiada pelo CNPq, ciclo 2020/2021, da Universidade Federal de Alagoas.

${ }^{2}$ Doutor em Educação. Docente do Centro de Educação e do Programa de Pós-graduação da Universidade Federal de Alagoas. Integrante do grupo de Pesquisa Gestão e Avaliação Educacional.

ORCID: http://orcid.org/0000-0001-5490-6690 E-mail: givanildopedufal@gmail.com / givanildo.silva@cedu.ufal.br

${ }^{3}$ Graduanda do curso de Pedagogia da Universidade Federal de Alagoas, integrante do grupo de Pesquisa Gestão e Avaliação Educacional e bolsista do PIBIC (UFAL/CNPq). ORCID: http://orcid.org/0000-0002-3815-6997

E-mail: dayane.carvalho@cedu.ufal.br
} 


\title{
The culture of evaluation and accountability in the post- 1990 educational reforms
}

\author{
Givanildo da SILVA \\ Dayane Queiroz dos Santos CARVALHO
}

\begin{abstract}
Educational practices on the school's "floor" are guided by the conceptions contained in educational policies, designated by administrative reforms. The objective of the research was to understand the role of the State and educational reforms in the culture of evaluation and accountability in Brazilian education, taking as a starting point the understanding that public education is a complex, dynamic and sandy field. The methodology was based on a qualitative approach from the perspective of exploratory research in a municipal public school in Maceió. The main results pointed out that the educational reforms implemented after 1990, which intensified the culture of evaluation and accountability, modified the organization of the school, attributing marketing principles in educational practice, through the managerial public administration.
\end{abstract}

Keywords: Evaluation culture. Accountability. Educational Policies. 


\title{
La cultura de la evaluación y la responsabilidad en las reformas educativas post-1990
}

\author{
Givanildo da SILVA \\ Dayane Queiroz dos Santos CARVALHO
}

\begin{abstract}
Resumen
Las prácticas educativas en el "piso" de la escuela están guiadas por las concepciones contenidas en las políticas educativas, designadas por las reformas administrativas. El objetivo de la investigación fue comprender el papel del Estado y las reformas educativas en la cultura de evaluación y rendición de cuentas en la educación brasileña, tomando como punto de partida el entendimiento de que la educación pública es un campo complejo, dinámico y arenoso. La metodología se basó en un enfoque cualitativo desde la perspectiva de la investigación exploratoria en una escuela pública municipal de Maceió. Los principales resultados señalaron que las reformas educativas implementadas después de 1990, que intensificaron la cultura de evaluación y rendición de cuentas, modificaron la organización de la escuela, atribuyendo principios de marketing en la práctica educativa, a través de la gestión pública gerencial.
\end{abstract}

Palabras clave: Cultura de evaluación. Responsabilidad. Políticas educativas. 


\section{Introdução}

As políticas educacionais são resultado de tensões, de conflitos e de embates que são travados na arena social, na intenção de consolidar uma determinada concepção de sociedade, mediante a concretização das reformas administrativas que repercutem na educação. No que se refere à avaliação e às políticas de responsabilização no contexto das reformas pós-1990, o Estado avaliador exime-se de seu papel, atribuindo a responsabilidade de suas funções para a comunidade escolar e local. De acordo com Johnson (1997, p. 91), o "Estado é a instituição social que mantém monopólio sobre o uso da força. O Estado é uma instituição social, o que significa que consiste de uma forma ou plano social de como várias funções devem ser desempenhadas”.

As práticas educativas no “chão” da escola são orientadas por meio das concepções postas nas políticas educacionais e viabilizam paradigmas que os grupos políticos defendem e manifestam em meio às diferentes ideologias presentes na sociedade, a partir de modelos pensados para redefinir as práticas sociais, configurando-se nas reformas estabelecidas pelo Estado, mediante suas ideologias políticas, culturais e econômicas. Entendendo-se ideologia como "um conjunto de crenças, valores e atitudes culturais que servem de base e, por isso, justificam até certo ponto e tornam legítimos o status quo ou movimentos para mudá-lo” (JOHNSON, 1997, p. 126).

As reformas educacionais são caminhos políticos para a concretização de anseios e de modificações da prática social, efetivadas por burocratas que idealizam o modelo de sociedade e das questões inerentes ao Estado, com a finalidade de possibilitar rupturas e permanências na forma de organização na administração pública e nas funções que são de responsabilidade do Estado. Desse modo, todos os governos, por meio de suas concepções políticas, desenvolvem reformas, as quais estão interligadas às necessidades/urgências, geralmente de cunho econômico, sociais de sua época, bem como às mobilizações da sociedade em prol de respostas para as problemáticas em questão.

O objetivo da pesquisa foi compreender o papel do Estado e das reformas educacionais na cultura de avaliação e de responsabilização na educação brasileira, tendo, como ponto de partida, a compreensão de que a educação pública é um campo complexo, dinâmico e arenoso, necessitando de reflexões acerca das diferentes orientações que são postas por meio das políticas educacionais em virtude das reformas educacionais pós-1990, no processo de redefinição do papel do Estado.

Na década de 1990, foram instauradas novas reorganizações administrativas no cenário brasileiro, as quais reverberaram na organização escolar, no currículo, na gestão e na cultura avaliativa, tendo, como pressuposto, a responsabilização dos profissionais da educação por resultados atribuídos à escola pelo Estado. Justifica-se que discussões como esta, a qual objetiva compreender 
as nuances das políticas e das reformas educacionais no “chão” da escola, apresentam relevância para o âmbito da pesquisa e da prática escolar, uma vez que o descortinamento desse cenário revela as tensões, as experiências e as vivências acerca do processo de controle, de pressão, das cobranças e das ações para o olhar sobre os impactos das reformas na educação brasileira, em especial, na pública.

A metodologia esteve pautada em uma abordagem qualitativa, tendo, como objetivo, a pesquisa exploratória em uma escola pública municipal de Maceió. Participaram da pesquisa 5 (cinco) profissionais da escola. O critério de escolha para participação foi ser profissional envolvido diretamente com a prova do SAEB na última aplicação das avaliações, em 2019. Assim, contribuíram com a pesquisa 3 (três) professores do $5^{\circ}$ ano, o coordenador pedagógico, que acompanhou esses professores, e a gestora da escola.

A coleta de dados deu-se por meio da aplicação do questionário on-line, devido à pandemia 4 , no período de 14 a 26 de fevereiro de 2021. A análise dos dados foi desenvolvida a partir da Análise do Conteúdo, na perspectiva de Bardin (2002), sendo categorias analíticas cultura de avaliação, responsabilização e políticas educacionais.

O texto está estruturado em três seções que se completam, além da introdução e das considerações finais. Na primeira, apresenta-se o pontapé inicial para a cultura das avaliações em larga escala e da responsabilização no contexto das reformas pós-1990. Na segunda seção, dialogase sobre as implicações da cultura de responsabilização para os profissionais da educação, por meio das orientações e das mudanças postas no currículo e avaliação escolar, na gestão e organização da escola pública. E, por fim, apresentam-se as vozes dos participantes sobre a cultura de avaliação e de responsabilização posta nas políticas educacionais, tendo como referências os testes padronizados.

\section{A década de 1990: o pontapé inicial para a cultura das avaliações em larga escala}

A década de 1990 apresentou mudanças relevantes na administração pública, por meio da reforma do Estado, realizada no primeiro mandato (1995-2002) do presidente Fernando Henrique Cardoso (FHC), com a criação do Ministério da Administração e Reforma do Estado (MARE), cujo ministro foi o economista Luiz Carlos Bresser Gonçalves Pereira.

O objetivo geral da reforma administrativa, de acordo com Plano Diretor da Reforma do Estado (1995), foi transitar de uma administração pública burocrática para a gerencial, na perspectiva de apresentar respostas à crise do Estado dos anos 1980 e à globalização da economia nacional que

\footnotetext{
${ }^{4}$ Doença causada pelo coronavírus, denominado SARS-CoV-2, a qual está presente em todos os países, causando conflitos sociais, políticos, culturais e sanitários.
} 
necessitava, segundo os idealizadores da reforma, ser internacionalmente competitiva para que o Estado brasileiro pudesse ser transformado e reconstruído à luz do modelo gerencial de administração, redefinindo suas funções em meio às questões sociais.

O paradigma de administração gerencial visava contribuir com ações que amenizassem a carga de responsabilidade do Estado, tendo como pressupostos: 1) descentralização do ponto de vista político, transferindo recursos e atribuições para os níveis políticos regionais e locais; 2) descentralização administrativa, através da delegação de autoridade para os administradores públicos, transformados em gerentes crescentemente autônomos; 3) organizações com poucos níveis hierárquicos ao invés de piramidal; 4) pressuposto da confiança (autonomia) limitada e não da desconfiança total; 5) controle por resultados, a posteriori, ao invés do controle rígido, passo a passo, dos processos administrativos; 6) administração pública moderna, eficiente, controlada por resultados, voltada para o atendimento ao cidadão-cliente (BRESSER-PEREIRA, 1995).

A administração pública gerencial inspirou-se na administração de empresas (BRESSERPEREIRA, 1995), transportando o pressuposto dessas ações para o setor público, tendo o discurso da qualidade total como a principal estratégia de gerenciamento a ser adotada pelas organizações do Estado. A reforma gerencial foi uma estratégia de gestão pública para o Estado brasileiro, com a finalidade de impulsionar as mudanças em diferentes dimensões sociais.

A reforma administrativa do Estado redefiniu as suas funções, apresentando mudanças na forma de conduzir os processos de aposentadoria dos servidores públicos, concretizou a privatização das empresas estatais, incentivou as organizações sociais como forma de desconcentrar e privatizar as responsabilidades, repercutindo nas políticas sociais, como saúde e educação, reduzindo o papel do Estado de executor ou prestador direto de serviços, mantendo-se na função de regulador e avaliador (BRESSER-PEREIRA, 1995).

No âmbito da educação, a reforma administrativa redefiniu mudanças na forma de condução das escolas, por meio da criação de programas focalizadores, como o Programa Dinheiro Direto na Escola (1995), políticas de avaliação em larga escala, por meio de testes padronizados, com o Sistema Nacional de Avaliação da Educação Básica (SAEB), e ênfase no ensino fundamental, no âmbito do financiamento, com a aprovação da Lei 9.424, de 24 de dezembro de 1996, a qual instituiu o Fundo de Manutenção e Desenvolvimento do Ensino Fundamental e de Valorização do Magistério (FUNDEF).

Além das políticas apresentadas, é valido sinalizar que a reforma do Estado desencadeou, por meio dos programas e políticas, novas configurações educacionais pautadas nos princípios da autonomia limitada, na responsabilização por resultados; na descentralização (desconcentração); na 
Qualidade Total; nas estratégias de mercado; na competição e na eficiência e na eficácia dos serviços desenvolvidos. Na visão de Casassus (1995), esses princípios foram disseminados pelos países da América Latina como possíveis alternativas para a superação das crises políticas, sociais e econômicas que eles estavam passando, com a falsa promessa da modernização administrativa, inspirada pelas experiências de países anglo-saxões (OLIVEIRA, 2015).

A busca por resultados educacionais e a responsabilização dos profissionais da educação foram princípios evidenciados na reforma do Estado, que perduram até os dias atuais, com maior ênfase, uma vez que "a administração pública gerencial enfatiza os resultados porque pressupõe que será capaz de punir os que falharem ou prevaricarem” (PLANO DIRETOR, 1995, p. 54). De acordo com os reformadores, a indicação de metas a serem cumpridas pelos servidores públicos, no caso da educação, os profissionais da área, deveria ser apresentada pelo Estado com a finalidade de os envolvidos estarem atentos para cumprirem as designações ou, caso contrário, poderiam ser penalizados.

O Plano Diretor do Aparelho da Reforma do Estado (1995, p. 54) sinalizava que:

A reforma concreta do aparelho do Estado ocorre na dimensão da gestão. É aí que a administração pública se torna mais efetiva e eficiente. É aí que ocorrem as mudanças culturais necessárias. É aí que as práticas administrativas gerenciais de fato ocorrem. É aí que se definem os indicadores de desempenho, que se treina e motiva o pessoal, que se desenvolvem estratégias flexíveis para o atingimento das metas estabelecidas.

A cultura de responsabilização e as novas orientações para a educação surgiram no contexto da influência neoliberal que apresentou, por meio da reforma do Estado, o modelo da gestão gerencial, perfazendo rupturas e agregando responsabilidades à escola pública e aos seus profissionais. Desse modo, a cultura de responsabilização foi sendo, gradativamente, inserida no âmbito dos espaços públicos, com a finalidade de alcançar os objetivos propostos pelos reformadores. A escola, como lugar coletivo e de responsabilidade do Estado, passou a ser vista como uma instituição na qual as comunidades local e escolar deveriam responder pelos resultados educacionais e, em algumas situações, pelo financiamento das atividades.

O Estado passou a conceber a escola e os seus profissionais como corresponsáveis pelo empreendimento educacional, muitas vezes, eximido-se de seu papel de provedor, apontando princípios gerenciais a serem seguidos na perspectiva de consolidar a cultura de responsabilização. Ela foi uma alternativa positiva para a gestão pública gerencial, uma vez que evidenciou o teor cultural de uma concepção política que tem em suas bases os princípios mercadológicos. 
A concepção posta nesse modelo é do Estado mínimo para as políticas sociais, congregando princípios e ações mercadológicos, relacionando a escola a uma empresa, na qual é necessário apresentar resultados, produtividade, eficiência e eficácia. Para Enguita (1994, p. 95-96), a palavra de ordem para a defesa dos princípios mencionados é a qualidade total, direcionando as políticas educacionais de cunho neoliberal com a justificativa da existência de uma qualidade em seu discurso. Nas palavras do autor:

Converte-se, além disso, em uma palavra de ordem mobilizadora, em um grito de guerra em torno do qual se devem juntar todos os esforços. Por sua polissemia pode mobilizar em torno de si os professores que querem melhores salários e mais recursos e os contribuintes que desejam conseguir o mesmo resultado educacional a um menor custo; os empregadores que querem uma força de trabalho mais disciplinada e os estudantes que reclamam maior liberdade e mais conexão com os seus interesses; os que desejam reduzir as diferenças escolares e os que querem aumentar suas vantagens relativas.

O diálogo acerca da qualidade da educação é complexo e envolve diferentes cenários e perspectivas, tornando-se uma seara densa. A redução da qualidade exclusivamente ao resultado das avaliações em larga escala traduz a pequenez na compreensão da complexidade educacional e da visibilidade do cenário social, político, econômico e cultural, o qual atinge as diferentes realidades educacionais existentes no Brasil.

As primeiras experiências de avaliações em larga escala no Brasil surgiram na década de 1930, tendo, seus primeiros ensaios, em 1980, nos estados do Paraná e Rio Grande do Norte, consolidandose como campo educacional em 1990, por meio SAEB como política nacional (CHIRINÉIA; BRANDÃO, 2015). Para Bauer (2012, p. 8), a década do pontapé inicial da cultura de responsabilização foi 1980, no entanto, a partir dos anos 1990, o desenho dessa cultura foi ganhando forma, concretizando os interesses dos idealizadores da reforma da época:

No Brasil, as avaliações de sistemas educacionais começaram a ser concretizadas no final da década de 1980, mais especificamente em 1987, com a proposição do Sistema Nacional de Avaliação do Ensino Público de $1^{\circ}$ grau (SAEP). Essa primeira experiência de avaliação de sistemas públicos de ensino, no nível de Ensino Fundamental, ensejada pelo Ministério da Educação e do Desporto (MEC) nos estados do Paraná e do Rio Grande do Norte, lançou as bases para uma política de avaliação federal mais abrangente que, atualmente, atinge os diversos níveis de ensino, do ensino fundamental à pós-graduação.

Os ensaios para a concretização da cultura da avaliação tornaram-se meios para as mudanças pós-1990, com destaque para o currículo e o modelo de gestão escolar gerencial. Connel (1995, p. 34) salienta que as reformas pautadas na estrutura da educação são oriundas de princípios neoliberais e mercadológicos, os quais contribuem para a exclusão e a desigualdade estrutural no sistema 
educacional, repercutindo no agir e no pensar da educação pública, especialmente para os filhos da classe trabalhadora.

Reformas no currículo e no sistema de avaliação custam caro, principalmente no que diz respeito ao tempo e à energia humana que exigem. O nível de recursos materiais destinados às escolas para grupos pobres ainda faz diferença, mesmo que concordemos que a qualidade da educação não depende da pintura nova das paredes do prédio onde funciona. [...] Dadas as importantes desigualdades nos recursos destinados às escolas, existe um forte argumento de justiça distributiva a ser feito, em favor de níveis muito mais altos de fundos para as escolas destinadas aos pobres e fundos mais altos para as escolas proletárias em geral.

As reformas desenvolvidas na educação, pós-1990, estiveram centradas na perspectiva de responder positivamente ao modelo mercadológico, por meio da influência dos empresários na construção das políticas educacionais e na busca pela inserção de propostas que fossem satisfatórias à consolidação de um modelo de sociedade que vislumbrasse o capital em detrimento do social.

Em relação ao currículo, as reformas postas vincularam as avaliações às orientações curriculares, especialmente com os Parâmetros Curriculares Nacionais (1997) e, atualmente, com a Base Nacional Comum Curricular (2017). Esses mecanismos direcionam as habilidades e as competências a serem trabalhadas com os estudantes, concretizando um currículo mínimo e prescritivo, o qual está inserido em uma política maior que visa adequar o currículo às avaliações em larga escala e estas aos ditames globais da lógica do mercado.

Na visão de Gomes (2016, p. 57), no âmbito da cultura avaliativa, a década de 1990 foi o palco das construções dos processos avaliativos em larga escala, inserindo a avaliação como pressuposto básico da mensuração da qualidade educacional do país.

Além do Saeb, a implantação do Exame Nacional do Ensino Médio (Enem), em 1998, o lançamento do Exame Nacional de Certificação de Jovens e Adultos (Encceja), em 2001, e a participação do Brasil em avaliações internacionais, como o Programme for International Student Assessment (Pisa) e o Segundo Estudo Regional Comparativo e Explicativo (Serce) contribuíram para fortalecer no País a cultura de avaliação e o compromisso com o monitoramento das políticas educacionais. No ensino superior foi instituído o Exame Nacional de Cursos, conhecido como Provão.

As estratégias para a mudança foram introduzidas, no contexto da educação, pós-1990, destacando-se a influência da política neoliberal, a qual responsabiliza as escolas e os profissionais pelos resultados educacionais percebidos por meio dos testes padronizados, bem como percebe-se, com muita ênfase, a ausência do Estado em áreas prioritárias, como a educação. Em síntese, o papel do Estado é avaliar e responsabilizar as escolas pelos resultados (BAUER, 2012), como sinalizavam as orientações do Plano Diretor do Aparelho da Reforma do Estado, em 1995, consolidando-se a cultura de responsabilização por meio das políticas educacionais. 
Em relação ao SAEB, política de Estado que perdura até os dias atuais, salienta-se o conceito de matriz de referência da avaliação que trabalha para elaboração de um conjunto de blocos e de matérias entre as séries e os anos na escala de proficiência para cada disciplina. Ele passou a avaliar a cada dois anos a proficiência dos estudantes nas disciplinas de português e matemática, com o objetivo de examinar a capacidade deles para desenvolver os conhecimentos obtidos aos longos dos anos, passando a identificar os níveis de aprendizagem alcançados pelos participantes.

Em 1996, iniciou-se a montagem da matriz de referência do SAEB, elaborada a partir de consulta nacional sobre as propostas curriculares praticadas no ensino fundamental e médio dos estados brasileiros. Ela incorporou também as Diretrizes Curriculares Nacionais e a regulamentação da Lei de Diretrizes e Bases da Educação Nacional, 9.394, de 20 de dezembro de 1996. Na prática, as matrizes são formadas por descritores, que podem ser definidos como a associação entre os conteúdos curriculares e as competências e habilidades aprendidas pelos alunos. Os descritores determinam o que os itens da prova devem cobrar dos estudantes, de acordo com a série cursada (GOMES, 2016).

Na década seguinte, nos anos 2000, mais especificamente em 2007, foi criado, pelo governo de Luiz Inácio Lula da Silva, o Índice de Desenvolvimento da Educação Básica (IDEB). Esse índice visa apresentar a qualidade da educação em cada estado e município, cada rede de ensino e cada escola, por meio dos resultados das avaliações realizadas pelo SAEB. A problemática posta nessa política é a redução, mais uma vez, do conceito de qualidade ao resultado de uma avaliação padronizada e minimalista, avaliando apenas duas disciplinas.

De acordo com Castro (2009, p. 34):

[...] os testes padronizados são instrumentos necessários, mas insuficientes para avaliar a melhora da qualidade da educação, principalmente os testes como SAEB e o Enem, adotados pelas políticas públicas, pois possuem um caráter restrito de avaliação. É importante considerar, nesse processo, não só os insumos, mas também outros indicadores como a cultura organizacional da escola, as práticas e as relações entre professores e alunos.

Entende-se que a avaliação é um processo complexo e precisa ser vivenciado em uma perspectiva democrática, de modo que todos os envolvidos sejam participantes nas decisões e nas construções propositivas. O modelo da avaliação em larga escala, como o SAEB e o IDEB, coloca em ação os princípios da eficiência, da eficácia e da produtividade. Nessa lógica, "somente a responsabilização da escola pelo sucesso ou fracasso escolar, sem levar em consideração outras variáveis que interferem no processo e que relegadas ou neglicenciadas pelas avaliações, pode comprometer o resultado” (CHIRINÉA; BRANDÃO, 2015, p. 475). 
As avaliações em larga escala têm o objetivo de mensurar a qualidade da escola como um todo, reverberando nas práticas dos professores, dos demais profissionais da escola e da proposta curricular vivenciada, a fim de alcançar os objetivos propostos. No entanto, há controvérsias acerca da padronização curricular, almejada pelas avaliações em larga escala, utilizadas para designar a qualidade da educação das escolas, isso porque cada instituição tem sua cultura, sua especificidade e seus modos de organização, repercutindo nas aprendizagens cotidianas.

De acordo com Dias Sobrinho (2005), a avaliação age sobre as mentalidades e as filosofias educativas e, a partir disso, define estilos de gestão, fornece elementos para tomadas de decisão, fixa determinados tipos de currículo, valoriza programas, legitima saberes e práticas, instrumenta políticas de regulação, de seleção social e de financiamento etc. Por isso, é um campo em disputas, dentro e fora do âmbito propriamente educacional. Como muitos são os valores envolvidos, é comum que a avaliação seja determinada nem tanto pelos educadores, mas, sobretudo, por grupos que detêm o poder político e econômico (DIAS SOBRINHO, 2005).

Na visão de Dias Sobrinho (2005), a proposta das avaliações em larga escala está sintonizada com a relação entre educação e economia. Essa perspectiva considera a educação como um negócio e visa ao interesse financeiro, tendo, como base orientadora, o interesse individual do Estado avaliador e não o bem comum da sociedade. Assim, a educação estaria visando ao lucro e não a sua própria qualidade social, na perspectiva de valorizar os profissionais da educação, contribuir com a estrutura das escolas, observar a realidade social dos estudantes e da comunidade local na qual a escola está inserida, entre outros elementos.

\section{As implicações da cultura de responsabilização para a educação}

Os processos educativos vivenciados no “chão" da escola são permeados de intenções e congregam, nas políticas educacionais, os interesses dos que a formulam. Desse modo, pensar acerca das implicações da cultura de responsabilização para os profissionais da educação remete ao papel social que estes assumem no contexto da educação. Na visão de Pansani (2011, p. 83), o papel social é a “conduta que se espera de um indivíduo, na sua relação com os outros membros do grupo. Tarefas decorrentes de um status, que devem ser realizadas por uma pessoa, ligadas e apreciadas positivamente por um círculo de pessoas nelas interessadas”.

Nessa dimensão, entende-se o papel que o Estado exerce sobre as políticas educacionais, observando essa constatação à responsabilização dos resultados para as escolas, consolidando, em algumas redes de ensino, premiação e/ou punição às escolas e seus profissionais. Freitas (2014) 
analisa que esse modelo de política avaliativa estimula a competição entre as escolas e os profissionais. Outra questão problematizada pelo autor é a exposição que a mídia faz desses resultados, apresentando as instituições que tiveram o maior e o menor desempenho, assim como seus respectivos municípios e estados.

No contexto da influência das políticas educacionais mais recentes, o atual Plano Nacional de Educação, Lei 13.005, de 25 de junho de 2014, na meta 7, apresenta que a qualidade da educação será avaliada mediante os resultados das avaliações em larga escala (IDEB | PISA ${ }^{5}$ ), confirmando, mais uma vez, a lógica dos resultados, orientada na reforma administrativa na década de 1990. Essa proposição evidencia a valorização das avaliações padronizadas, destacando com ênfase o papel social que a educação e os seus profissionais precisam trilhar para responder, satisfatoriamente, as intenções do sistema (DOURADO; FILHO; SAVIANI, 2014). Nessa perspectiva, Filho (2014, p. 232) reflete que:

Os indicadores de avaliação da qualidade da educação (Ideb e Pisa) não atendem as demandas para garantir a aprendizagem, o que fazem é estimular a competição entre as escolas para obter a melhor posição no ranqueamento divulgado pelos meios de comunicação e pelos governos, muitos dos quais formulam políticas de bônus e premiação salarial para os profissionais da educação, provocando diversos conflitos no ambiente escolar entre os trabalhadores em educação.

Os resultados dos testes padronizados não mostram o retrato fiel das condições de qualidade das escolas que são avaliadas. Elementos como gestão escolar; formação e condições de trabalho docente; ambiente escolar e suas estruturas; prática pedagógica e avaliativa; o acesso, a permanência e o sucesso dos estudantes na escola; valorização profissional; relações culturais, sociais e econômicas (CHIRINÉA; BRANDÃO, 2015) não são valorizados no processo de mensuração dos resultados. Além desse aspecto, não há uma análise acerca da diversidade regional do Brasil, as diferenças socioeconômicas dos estados e dos municípios, os quais se configuram em importantes pressupostos para as reflexões educacionais.

Neste aspecto, percebe-se a lógica do mercado inserida na organização das escolas. Os princípios da eficiência, da eficácia e da produtividade são cobrados aos envolvidos, sendo estes punidos ou premiados mediante o seu desempenho, fazendo menção aos objetivos do Plano Diretor do Aparelho e Reforma do Estado (1995). As práticas pedagógicas, por meio das orientações das

\footnotetext{
${ }^{5}$ O Programa Internacional de Avaliação de Estudantes (PISA), tradução de Programme for International Student Assessment, é um estudo comparativo internacional realizado a cada três anos pela Organização para a Cooperação e Desenvolvimento Econômico (OCDE). O PISA oferece informações sobre o desempenho dos estudantes na faixa etária dos 15 anos, idade em que se pressupõe o término da escolaridade básica obrigatória na maioria dos países.
} 
políticas educacionais, estão formando sujeitos competitivos, individualistas, produtivos, eficientes e eficazes, prontos para atuar no mercado, como preconiza a lógica neoliberal.

A contradição evidenciada na política educacional é resultado das múltiplas forças dos grupos políticos, os quais sinalizam os seus principais interesses por meio da prática educacional. No caso do Estado brasileiro, a cultura das avaliações em larga escala instaurou-se nas práticas escolares e nas diferentes redes e sistemas de ensino, uma vez que as políticas educacionais possibilitam o aprimoramento e a difusão dos seus ideais, valorizando as escolas e as redes que têm melhor desempenho nos testes.

De acordo com Afonso (2006), o Estado passa de provedor para avaliador, o qual vê, nos testes padronizados, o mecanismo para cobrar melhorias educacionais dos profissionais e da comunidade em que a escola está localizada. O Estado avaliador ou gerencial não visualiza que a melhoria da qualidade da educação dá-se mediante a existência de diferentes mecanismos, os quais estão atrelados ao seu papel social para a construção de uma sociedade inclusiva e dinâmica. O modelo de avaliação proposto pelas políticas educacionais contribui para a exclusão dos já excluídos e a invisibilidade dos invisíveis, os quais, predominantemente, estão na escola pública.

De acordo com os estudos de Freitas (2014), a organização escolar, na atualidade, tem intensificado as ações para responder positivamente aos apelos do sistema educacional, em decorrências das avaliações. Dentre os aspectos apresentados pelo autor, destacam-se a preparação dos estudantes para a realização das provas padronizadas, a divulgação do resultado do desempenho das escolas, dos municípios e dos estados e os diferentes papéis que os profissionais da educação exercem para adequar-se às exigências postas pela política. Esse processo envolve diferentes estratégias, pressões aos profissionais e organização das redes de ensino, a fim de que os resultados finais sejam concretizados nos índices educacionais.

Para Chirinéa e Brandão (2015, p. 477):

[...] entende-se que escolas e sistemas de ensino, principalmente os municipais, sentindo a pressão para se enquadrar nas exigências impostas pelos testes ou, no limiar de uma saída "estratégica", para burlar o IDEB, treinam os alunos para a realização das provas ou utilizam outros meios, mais criativos e menos ortodoxos, como, por exemplo, induzir os alunos que apresentam maiores dificuldades de aprendizagem a faltar no dia da aplicação das avaliações ou reprová-los para que não cheguem aos $5^{\circ}$ e $9^{\circ}$ anos do Ensino Fundamental, no período de realização das provas.

A realidade da escola pública é densa e perpassa pelas condições estruturais e dinâmicas que os seus participantes vivenciam, sinalizando a complexidade da atuação dos profissionais. Além da tensão social, há as proposições das políticas educacionais que contribuem para o processo de 
exclusão educacional, da cobrança e das pressões por resultado. Nessa lógica, nota-se a influência de cunho neoliberal nas artimanhas que são realizadas pela comunidade escolar para responder às pressões do sistema.

Essas ações implicam diretamente a forma como os profissionais da educação compreendem o papel social da escola, enquanto instituição que deveria prezar pela inclusão, pela oportunidade e pelas vivências dinâmicas. De modo geral, essa percepção possibilita a reflexão sobre os caminhos que os projetos sociais estão direcionando para a educação brasileira, bem como as saídas de emergências que esses profissionais estão configurando no contexto da política, apontando que as múltiplas estratégias desenvolvidas pelas escolas são caminhos possíveis para a realização positiva dos apelos do Estado.

As implicações do modelo de avaliação em larga escala no “chão” da escola são perceptíveis na medida em que as dimensões qualitativas das avaliações são “esquecidas” em detrimento das quantitativas, indo de encontro ao que preconiza o artigo 24 da LDB/1996. As orientações das redes e dos sistemas de ensino são pautadas em possibilitar que os profissionais da educação atendam aos apelos do Estado, concretizando as propostas das avaliações nas ações cotidianas.

Essas referências sinalizam a função social que o modelo de educação está propondo para a sociedade, modificando a concepção de educação e de práticas educativas com a finalidade de estruturar um projeto social fundamentado no viés neoliberal. Nessa perspectiva, as políticas educacionais pós-1990 modificaram os princípios da formação docente, os currículos e os tempos escolares, o paradigma de gestão escolar e a postura profissional dos envolvidos, implicando, assim, a formulação de estratégias hegemônicas que repercutem no "chão” da escola e, consequentemente, nas ações individuais dos cidadãos.

\section{As avaliações padronizadas e o papel da escola: as vozes dos profissionais}

A escola que a pesquisa foi realizada compõe a rede pública municipal de educação de Maceió, localizada na parte alta do município. Atende aproximadamente 775 estudantes, nos turnos matutino, vespertino e noturno, do $1^{\mathrm{o}}$ ao $5^{\circ}$ ano e na modalidade da Educação de Jovens, Adultos e Idosos (EJAI). No ano letivo de 2021, a escola possui um total de 31 turmas. Como já sinalizado, participaram da pesquisa 5 (cinco) profissionais da escola, os quais estiveram envolvidos diretamente com a prova do SAEB em 2019. O quadro 1 sistematiza algumas características que foram evidenciadas pelos profissionais em relação ao tempo de atuação na escola e à formação inicial e continuada. 
Quadro 1: Características dos participantes da pesquisa

\begin{tabular}{|c|c|c|}
\hline Participante & Tempo de atuação na escola & Formação inicial e continuada \\
\hline Professor I (PI) & 5 a 10 anos & Pedagogia / Psicopedagogia Institucional \\
\hline Professor II (PII) & 5 a 10 anos & $\begin{array}{c}\text { Pedagogia/ Licenciatura em Teatro /Pós em } \\
\text { Metodologias do Ensino da Arte. }\end{array}$ \\
\hline Professor III (PIII) & 1 a 5 anos & $\begin{array}{c}\text { Magistério / Ensino Superior incompleto } \\
\text { (Ciências Biológicas) }\end{array}$ \\
\hline Diretor Escolar (DE) & 10 a 15 anos & Pedagogia \\
\hline Coordenador Pedagógico (CP) & 1 a 5 anos & \begin{tabular}{c} 
Pedaia \\
\hline
\end{tabular}
\end{tabular}

FONTE: Sistematização dos pesquisadores.

Como é possível perceber, nas informações apresentadas no quadro 1, os profissionais têm uma formação inicial coerente com as recomendações postas pelos dispositivos legais, quando indicam que a formação seja, no mínimo, em nível superior. Em relação aos professores, apenas um (PIII) tem o Curso Normal, antigo magistério, e não possui graduação na área específica de sua atuação. O tempo de atuação dos profissionais na escola é satisfatório para conhecer a dinâmica desenvolvida, apresentando a cultura da escola e os caminhos trilhados sobre os propósitos da avaliação no contexto das avaliações em larga escala, como o SAEB.

A cultura escolar é um mecanismo importante para ser levado em consideração, uma vez que a construção da cultura é dinamizada pelas orientações e percepções dos diferentes atores escolares, os quais trazem dimensões da formação, da visão de mundo e de escola, bem como as interferências externas oriundas das políticas educacionais e das normativas desenvolvidas pelos órgãos superiores, como as secretarias de educação. A cultura das escolas é dinâmica e perpassa por diferentes contextos, atribuindo valores, saberes e inspirações a partir da realidade da comunidade escolar, ocasionando rupturas, permanências e criando novas ações e posturas.

No âmbito da avaliação, as escolas são impulsionadas a realizar diferentes estratégias para responderem positivamente ao sistema, de modo que atenda aos apelos e às proposições das políticas educacionais. Desse modo, a avaliação torna-se um instrumento das políticas de responsabilização, como processo de construção de uma cultura avaliativa em múltiplas dimensões, destacando-se, nesse contexto, as aprendizagens dos estudantes.

Essa cultura de avaliação modifica as formas de organização das escolas, o currículo, as posturas pedagógicas e as estratégias realizadas para responder à dinâmica das políticas. As intenções das políticas de avaliação estão pautadas na lógica neoliberal, por meio do Estado avaliador, tendo a produtividade, a eficácia e a competição como perspectivas de vivências no “chão” da escola. Nessa 
dimensão, como salienta Casassus (1995), as políticas educativas são resultado de um projeto de sociedade, no qual a educação tem o propósito de contribuir por meio das organizações curriculares e os objetivos pautados na forma de conduzir as práticas e as experiências.

Na visão de Casassus (1995), a América Latina, pós-1990, sofreu interferências dos organismos multilaterais, os quais foram importantes para implantar políticas educacionais que direcionaram princípios neoliberais, responsabilizando a comunidade escolar por resultados, camuflados pelo discurso da modernização e da busca pela qualidade da educação pública. Desse modo, “o objetivo fundamental que subjaz na modernização educativa é conseguir aumentar a eficácia e a eficiência do sistema” (CASASSUS, 1995, p. 14).

Cabe refletir que as mudanças educacionais são importantes, principalmente, em um contexto no qual a sociedade é dinâmica e o movimento social faz parte das múltiplas dimensões, incluindo a escola. No entanto, nos moldes que foram instituídos na América Latina, por meio de políticas verticalizadoras, não foram favoráveis para a construção da identidade educacional pautada nos anseios da comunidade escolar e local. Para Casassus (1995), essas mudanças estiveram centradas na gestão, na formação dos professores, no currículo e na cultura da avaliação.

Acerca do processo de cultura de avaliação, as escolas desenvolvem diferentes estratégias para alcançar as projeções dos resultados educacionais postas nas avaliações em larga escala. Os profissionais, participantes da pesquisa, relataram que são necessárias diferentes ações, salientado que:

Estudo dirigido, leituras de diversos gêneros textuais, simulados (P1).

Reforço nas disciplinas de base, simulados de acompanhamento (P2).

Além dos estudos em sala, aulas práticas, jogos que proporcionam mais interação, gincanas com diversos desafios que levem os alunos a questões semelhantes aos da prova do IDEB (P3).

Tem um ano bem intenso de simulados e avaliação e apoio pedagógico mais atuante (DE).

Primeiramente, nos sentamos para discutirmos sobre as propostas e orientações propostas pela SEMED, após isso, fizemos uma adequação do que foi proposto, adaptando a nossa realidade. Depois acolhemos as ideias e sugestões dos professores já experientes nessas avaliações externas (CP).

Os mecanismos evidenciados sinalizam aspectos que refletem sobre a cultura da avaliação e a lógica imposta pelo sistema aos profissionais. A busca por melhores resultados é uma dimensão que faz com que aconteça a intensificação das propostas de testes avaliativos com maior frequência, bem 
como a ênfase nas disciplinas de língua portuguesa e matemática, com a finalidade de os estudantes estarem aptos a responderem com satisfação às avaliações externas (CHIRINÉA; BRANDÃO, 2015).

Há uma fragmentação no currículo escolar e na formação integral dos estudantes quando não há evidência das múltiplas dimensões e saberes no ato educativo (CHIRINÉA; BRANDÃO, 2015). As avaliações externas, como o SAEB, enfatizam apenas duas disciplinas, as quais são referências para os profissionais da educação no processo de preparação dos estudantes.

Os profissionais da educação são convocados a dinamizar o ato pedagógico, construindo estratégias para que os estudantes estejam a par dos conhecimentos que serão cobrados nas avaliações. Essa lógica tira a autonomia da escola e dos profissionais em desenvolverem ações que estejam atreladas aos saberes da comunidade escolar e local, respondendo às orientações das políticas educacionais e da proposta dos governos (FREITAS, 2014).

Foram apresentadas aos participantes da pesquisa diferentes estratégias pedagógicas que, supostamente, contribuem para o sucesso do resultado do IDEB na escola pública, sendo solicitado que marcassem as alternativas vivenciadas pela escola. $\mathrm{O}$ resultado das indicações está posto no gráfico 1.

\section{GRÁFICO 1: Estratégias Pedagógicas utilizadas pela Escola}

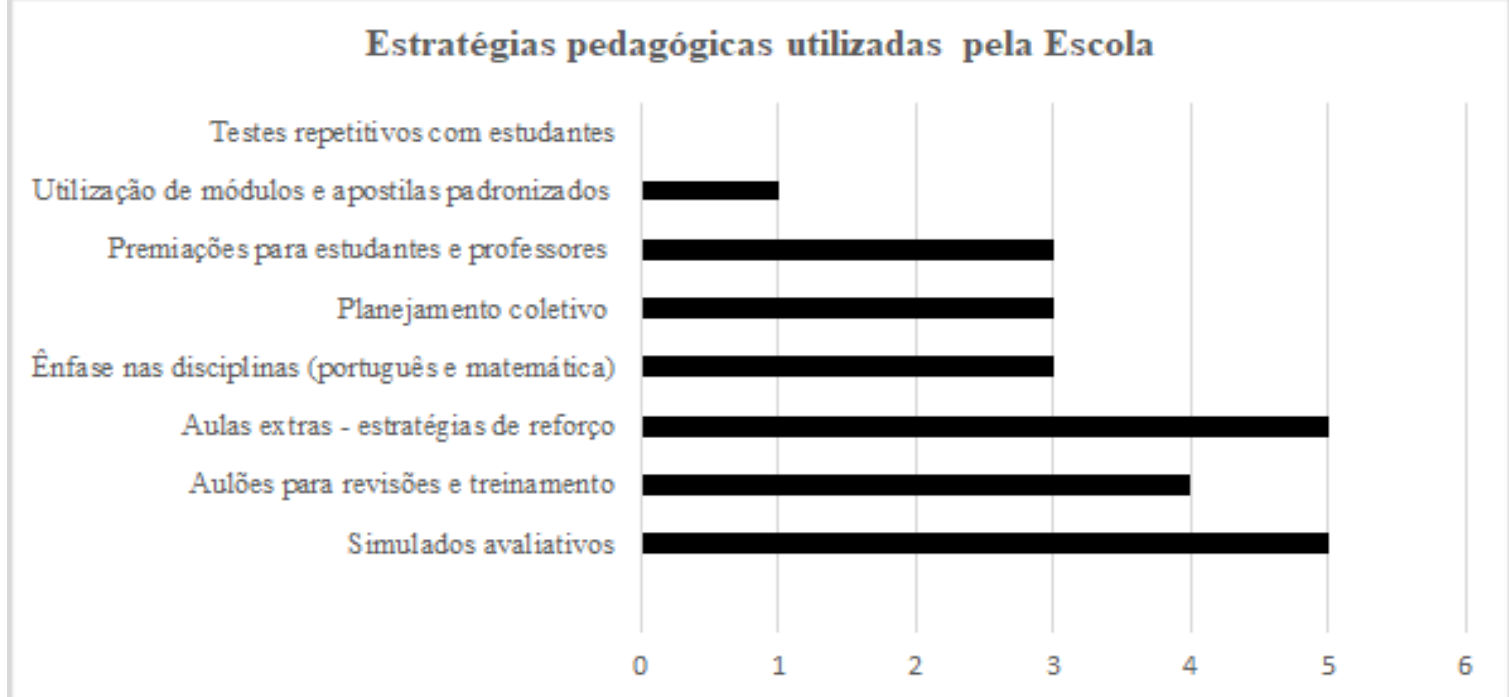

FONTE: Sistematização dos pesquisadores

As indicações apontadas são reflexo da prática escolar e da cultura avaliativa desenvolvida no ato educativo dos participantes. De modo geral, os resultados mostram que a escola desenvolve estratégias que possibilitam aos estudantes estarem aptos a realizarem, com sucesso, as avaliações externas. Para melhor compreensão das respostas, aponta-se que, em relação aos simulados avaliativos, a execução de aulas extras como estratégias de reforço e a ênfase nas disciplinas (português e matemática), os cinco profissionais destacaram que há a vivência dessas estratégia na 
escolas; quatro (PI; PII; DE; CP) indicaram a existência de aulões para revisões e treinamento de questões; três (PII; PII; DE) assinalaram a importância do planejamento coletivo para dialogar sobre os desafios enfrentados; Acerca das premiações para estudantes e professores com melhores resultados, obteve-se três (PIII; DE; CP) respostas; e um (CP) participante sinalizou a existência de utilização de módulos e apostilas padronizados. Nenhum dos participantes indicou a vivência de testes repetitivos com estudantes para o alcance dos bons resultados.

As estratégias utilizadas pela escola são condizentes com a possibilidade de construção de um modelo avaliativo que favorece a dinâmica posta pela política educacional, na intenção de direcionar as escolas ao processo avaliativo, bem como às artimanhas direcionadas pela lógica neoliberal (CHIRINÉA; BRANDÃO, 2015). De modo geral, cada escola, ao seu modo, constrói saídas de emergência para responder aos apelos da política e estar em sintonia com as diretrizes educacionais contemporâneas.

Compreendendo a escola como um espaço dinâmico e formado por diferentes pessoas, histórias e proposições, as quais têm funções definidas para o desenvolvimento das atividades escolares, foi questionado aos participantes o papel que cada um realiza na incumbência de alcançar um resultado positivo no IDEB. As respostas foram diversas, a partir da função desempenhada por cada participante:

Dar aulas onde os alunos sintam-se empolgados a aprender, com diversificadas metodologias (PI).

Aulas que proporcionem aprendizagem (PII).

Instruir, direcionar e motivar os alunos e levá-los a uma aprendizagem satisfatória para alcançarmos um bom resultado (PIII).

Auxiliar e buscar material para facilitar a aplicação das atividades (DE).

Coordenar as práticas pedagógicas junto à equipe de professores (CP).

No processo de organização da escola, todos os participantes têm uma função específica (FREITAS, 2014), com a finalidade de o trabalho alcançar os seus propósitos planejados. No constructo da gestão dos resultados das avaliações externas não é diferente, "provocando diversos conflitos no ambiente escolar entre os trabalhadores em educação” (FILHO, 2014, p. 232), uma vez que os envolvidos são convocados a realizarem diferentes ações para a construção de resultados positivos, indo ao encontro da política educacional em pauta.

A cultura da avaliação na escola mobiliza todos os participantes, com a finalidade de concretizar os anseios dos órgãos externos à escola, bem como os da própria escola em alcançar resultados que 
sejam favoráveis às estimativas projetadas. Diretores e coordenadores têm a função de estimular os professores ao "treinamento" dos estudantes para os testes que serão realizados; os professores, por sua vez, são pressionados a fazer com que os estudantes estejam preparados para realizar os testes padronizados (CHIRINÉA; BRANDÃO, 2015), alcançando os propósitos do sistema e da dinâmica posta nas políticas educacionais.

As proposições sobre as estratégias desenvolvidas pela escola refletem acerca da sua inserção no contexto das políticas de avaliação. Há uma dinâmica interna que mobiliza os seus participantes (FILHO, 2014), com a finalidade de adequar-se às projeções apresentadas pelos órgãos superiores, mesmo, tendo realidades complexas a serem pensadas e designadas no processo de construção das políticas educacionais.

O ritmo e o tempo da escola no período de preparação dos estudantes para a realização das avaliações externas são complexos, necessitando de modificações na organização e gestão da escola e na sala de aula, bem como a ruptura do currículo escolar pautado nas múltiplas disciplinas, a fim de estabelecer maior conexão com a língua portuguesa e a matemática, componentes curriculares avaliados no SAEB. Em relação às modificações realizadas na gestão pedagógica, na escola e na sala de aula, em períodos de avaliações em larga escala, os participantes mencionaram que:

Pequenos simulados, reforço português e matemática (PI).

Preparo para as avaliações, por meio de comportamentos que levam um melhor aprendizado dos alunos (PII).

A escola volta sua proposta para avaliações pertinentes às provas. Na sala de aula, trabalhamos mais simulados, assim como as avaliações na mesma proposta do formato da prova (PIII).

Sem modificar nada pois já atuamos assim nos outros anos também...na base de troca de conhecimento e ajudando uns aos outros (DE).

Todo o foco da escola se volta para a realização dessas provas (CP).

Nota-se a ênfase acerca da predominância em trabalhar apenas as disciplinas avaliadas, assim como os processos pedagógicos estarem centrados na realização das provas. A dinâmica escolar, em meio às pressões educacionais, é alimentada por direcionamentos que sinalizem contribuições para a construção de estratégias exequíveis que favoreçam aos professores trabalharem com os estudantes por meio de testes repetitivos e treinamentos (CHIRINÉA; BRANDÃO, 2015), muitas vezes, sem sentido. 
O contexto no qual se encontram os profissionais não é favorável para a compreensão das complexas relações estabelecidas na cultura das avaliações externas. O arcabouço político não contribui para o processo de descortinamento das análises e das reflexões sobre os limites desse modelo de avaliação que repercute na forma organizativa do ato pedagógico e da autonomia do trabalho docente.

O modelo posto nas avaliações em larga escala direciona e responsabiliza os profissionais para a concretização de resultados positivos, sistematizando cobranças no ato pedagógico em termos quantitativos. Os participantes mencionaram que:

Existe uma cobrança maior, para que o aluno obtenha bom desempenho (PI).

Sim, de fato a cobrança é maior, faz-se necessário muitas atitudes pedagógicas para que se obtenha um melhor resultado (PII).

Somos convocados a fazer um diagnóstico preciso desde o início do ano letivo, para descobrirmos as reais necessidades de cada aluno em si. E assim podermos traçar estratégias que contemplem a todos. A cada dois meses vendo e revendo os resultados se estamos ou não no caminho certo (PIII).

Acompanhamento do Programa Escola $10^{6}$ tem um apoio maior pois temos um articulador pedagógico (DE).

Devido à alta pressão causada pelas instituições superiores, todos os servidores das escolas são pressionados a alcançar resultados, e isso, é um pouco frustrante, muitas cobranças sem muitas vezes não dá condições para tanto trabalho (CP).

A busca por resultados torna-se o elemento central na construção das propostas educativas, com o objetivo de construir caminhos que contribuam com as aprendizagens dos estudantes, conforme orientam as políticas educacionais. De acordo com os depoimentos, a pressão por resultados é uma cultura vivenciada na tentativa de que os profissionais da escola sintam-se responsáveis pelos resultados, os quais não são oriundos das questões pedagógicas, envolvendo outros fatores (econômicos, sociais, políticos e culturais) que marcam a vida escolar dos estudantes.

O diálogo que se tece acerca da pressão aos profissionais da educação em busca de resultados pelas escolas é permeado por múltiplos processos, em que se centra o papel do Estado na possibilidade de melhorias educacionais para os envolvidos. A execução de uma educação de boa qualidade, a qual atende diferentes perspectivas, é exclusivamente do Estado, oferecendo estruturas nos prédios,

\footnotetext{
${ }^{6}$ O Programa Escola 10 é uma política de governo do estado de Alagoas, em regime de colaboração com os municípios, com a finalidade de contribuir com os resultados do IDEB. Há formação para os profissionais das diferentes redes de ensino, o qual denomina-se de Articulador Pedagógico, e distribuição de cadernos prontos com questões para serem trabalhas com os estudantes, favorecendo o treinamento da prova do SAEB.
} 
valorização social e salarial aos profissionais, formação continuada para eles, entre outras dimensões (CONNEL, 1995).

De modo geral, a busca pela qualidade, posta nas políticas educacionais, nos moldes do resultado do IDEB, camufla a realidade da educação brasileira. O discurso da qualidade da educação é oriundo da década de 1990 (CONNEL, 1995; CASTRO, 2009), em meio aos anseios da política neoliberal e está presente em diferentes plataformas dos governos, na tentativa de ludibriar a população em meio à defesa da educação.

As políticas educacionais, como o atual Plano Nacional de Educação, defendem que a qualidade seja relacionada aos resultados do IDEB, disseminando a ilusão de que os resultados apresentam o retrato fiel da educação brasileira. Os profissionais, participantes da pesquisa, foram questionados sobre a relação existente entre os resultados do IDEB e a eficácia da qualidade pedagógica desenvolvida nos trabalhos da escola. Apenas 1 (um) respondeu que não (PI) não há relação; 3 (três) responderam que em partes (PII; PIII; CP); e 1 (um) respondeu que sim (DE).

Percebe-se, por meio das revelações dos dados, que alguns profissionais da educação foram convencidos pelas orientações/discursos políticas de que o resultado do IDEB tem uma forte relação com a qualidade da educação ofertada nas escolas pelos profissionais. Não há, nesse contexto, uma leitura do retrato escolar, das condições de trabalho, do público escolar, enfim, de elementos que contribuem para a relação entre os resultados do IDEB e os trabalhos realizados na escola (FILHO, 2014).

A defesa que se apresenta é a de que as avaliações em larga escala são elementos para serem analisados e dimensionados como caminhos para possíveis melhorias, diagnósticos para os profissionais da escola e um elemento para que se efetivem políticas educacionais pautadas nos resultados, no sentido de contribuir com a escola, com a formação dos profissionais e a realidade educacional do país (CHIRINÉA; BRANDÃO, 2015). A lógica impressa vai de encontro a essas sinalizações, responsabilizando a escola e os seus profissionais pelos resultados.

Neste sentido, a evidência de uma escola de qualidade vai além dos resultados do IDEB, compreendendo que a categoria qualidade tem sentido multidimensional, a depender da visão de mundo e do lugar em que se vivencia a educação. Para os participantes da pesquisa, o que demonstra a qualidade é:

A escola que possa proporcionar vários tipos de aprendizagem, a escola que tem apoio dos pais, a escola que tenha todos os recursos materiais e humanos (PI).

Uma escola que encontre apoio da gestão, apoio da comunidade escolar, recursos humanos e materiais (PII). 
Uma equipe comprometida, onde cada um fazendo a sua parte, forma um todo com bons resultados (PIII).

Uma equipe pedagógica bem preparada e motivada. Uma família atuante. Alunos com sede de aprender (DE).

Pessoas felizes, com bons salários, estrutura física adequada para realização de práticas pedagógicas satisfatórias, material pedagógico de qualidade, equipamentos tecnológicos disponíveis para todos os envolvidos (CP).

As proposições evidenciadas estão em consonância com a defesa de que a qualidade da educação é um processo construído por diferentes aspectos e que o Estado tem o papel de responsabilizar-se pela sua concretização. A evidência da qualidade da educação posta nas políticas educacionais atuais não possibilita a reflexão sobre questões que mobilizam o ato pedagógico, a gestão e organização da escola, como a formação dos profissionais, a construção coletiva do Projeto Político-Pedagógico e do currículo escolar, a valorização social dos profissionais, a vivência da gestão democrática, condições de trabalho, entre outras.

A qualidade da educação é um mecanismo complexo e a cultura da avaliação posta nas políticas educacionais não vislumbram as dimensões sinalizadas. Compreende-se que essa cultura foi sendo designada no “chão” da escola pós-1990, no contexto da reforma do Estado. Assim, as promessas da ordem neoliberal por mais democracia, mais eficácia, mais recursos, mais eficiência, mais qualidade (CASASSUS, 1995) foram sendo atribuídas na prática escolar.

De modo geral, “novas” roupagens, inspiradas pela gestão gerencial, descortinam as intenções políticas do Estado em responder aos anseios do mercado e de seus idealizadores. A escola, nessa visão, passa a ser gerida como uma empresa, em busca de resultados. Os estudantes, vistos como cidadão-cliente (BRESSER-PEREIRA, 1995), e os profissionais da educação, como operários que precisam responder aos apelos do "patrão”, representado pelo Estado. Assim, “ao predominar o monopólio estatal em matéria educativa, os conteúdos educacionais são definidos pelas necessidades que o Estado tem de gerar uma ampla base cidadã. Uma educação na qual o público tem sido apropriado pelo Estado” (CASASSUS, 1995, p. 111), bem como a forma de organização escolar, a prescrição do currículo e o modelo avaliativo, por meio da centralização posta pelo modelo de gestão gerencial.

\section{Considerações finais}

A política educacional, por meio de suas estruturas organizativas, normatiza e legitima direcionamentos para a concretização de modelos de avaliação, de currículo e de gestão da educação, 
com a finalidade de referenciar a concepção política e social dos grupos que estão no poder. Dessa forma, percebe-se que a educação é um campo complexo, permeado de interesses e de conflitos entre os diferentes atores e movimentos sociais.

As mudanças ocasionadas na educação são frutos de um projeto de sociedade estabelecido pelo Estado brasileiro, sob a influência dos organismos internacionais, com o propósito de alcançar os objetivos do capital, tendo a educação como dimensão basilar para favorecer os anseios do mercado. As políticas instauradas desde as décadas de 1980 e 1990 são favoráveis a esses princípios, constituindo projetos e modelos sociais que sinalizam um rompimento com a educação transformadora para uma educação cuja orientação é a reprodução, que prepara para a competição, a padronização, a produtividade e a exclusão.

As avaliações em larga escala estão presentes no “chão” da escola pública. Estas, por sua vez, provocam diferentes estratégias dos profissionais da educação com a finalidade de alcançar as metas projetadas pelos órgãos governamentais, viabilizando uma concepção de educação marcada com propósitos meramente quantitativos, indo de encontro ao modelo de avaliação postos nos dispositivos legais que regulamentam a educação brasileira.

Problematizar essas nuances, tendo, como base, o “chão” da escola, é um importante exercício intelectual, a fim de perceber os processos de organização e os encaminhamentos que as políticas educacionais estão projetando para a educação básica no processo de construção da concepção de sociedade e nos direcionamentos para a atuação docente. Nessa percepção, destaca-se a intensa cultura da avaliação e da responsabilização dos profissionais da educação pelos resultados dos índices educacionais pós-1990.

Os modelos de educação postos pelas políticas educacionais são estabelecidos de modo unilateral, tendo o objetivo de preparar os cidadãos para o mercado de trabalho, para a competição empregada pelo sistema capitalista, emergindo na competição, no individualismo e na desigualdade social. Esses elementos são frutos de um sistema que tem o Estado como condutor de princípios que não garantem as políticas sociais para todos. Desse modo, a educação está inserida nessa realidade, tornando-se uma ponte para o estabelecimento de um modelo de sociedade excludente.

A educação é o caminho para estabelecer práticas que sinalizem a ética, a solidariedade, a empatia e a inspiração. Em síntese, cabe fazer a defesa da proposta da educação pública referenciada socialmente, a qual viabiliza oportunidades de inclusão, de participação, de envolvimento de todos os agentes sociais, congregando os diferentes interesses a fim de construir coletivamente uma educação pública democrática que inspire os cidadãos a modificar a sua realidade, por meio da transformação política e educacional. Eis, portanto, o desafio! 


\section{Referências}

AFONSO, A. J. Avaliação Educacional: regulação e emancipação para uma sociologia das políticas avaliativas contemporâneas. São Paulo: Cortez, 2006.

BARDIN, L. Análise de conteúdo. Trad. Luís Antero Reto e Augusto Pinheiro. Lisboa: Edições 70, 2002.

BAUER, A. Estudos sobre Sistemas de Avaliação Educacional no Brasil: um retrato em preto e branco. Revista @mbienteeducação, São Paulo, v.5, n.1, p. 7-31, jan./jun., 2012. Disponível em $<$ http://publicacoes.unicid.edu.br/index.php/ambienteeducacao/article/view/115>, acesso em 5 de abr. de 2021.

BRASIL. Constituição Federal de 1988. Brasília, 1988.

BRASIL. Lei n. 13.005, de 25 junho de 2014: Plano Nacional de Educação. Brasília, DF, 2014.

BRASIL. Lei n. 9.394, de 20 de dezembro de 1996: estabelece as diretrizes e bases da educação nacional. Brasília, DF: Biblioteca Digital da Câmara dos Deputados, 1996.

BRESSER-PEREIRA, L. C. Reflexões sobre a reforma gerencial brasileira de 1995 . Revista do Serviço Público, v. 50, n. 4, p. 5-30, out./dez. 1999. Disponível em:

<https://revista.enap.gov.br/index.php/RSP/issue/view/66> , acesso em 31 de mar. de 2021.

CASASSUS, J. Tarefas da Educação. Campinas, SP: Autores Associados, 1995.

CASTRO, A. M. D. A. A qualidade da educação básica e a gestão da escola. In: FRANÇA, M.;

BEZERRA, M. C. (Org.). Política educacional: gestão e qualidade do ensino. Brasília, Líber, 2009.

CHIRINÉA, A. M.; BRANDÃO, C. F. O IDEB como política de regulação do Estado e legitimação da qualidade: em busca de significados. Ensaio: Avaliação de Políticas Públicas Educacionais, v. 23, n. 87, p. 461-484, abr./jun. 2015. Disponível em $<$ https://www.scielo.br/pdf/ensaio/v23n87/0104-4036-ensaio-23-87-461.pdf $>$, acesso em 4 de abr. de 2021.

CONNEL, R. W. Pobreza e Educação. In: GENTILI, P. (Org.). Pedagogia da Exclusão: crítica ao neoliberalismo em educação. Petrópolis, RJ: Vozes, 1995.

DIAS SOBRINHO, J. Avaliação como instrumento da formação cidadã e do desenvolvimento da sociedade democrática: por uma ético-epistemologia da avaliação. In: RISTOFF, D.; ALMEIDA JUNIOR, V. P. (Orgs.). Avaliação participativa: perspectivas e desafios. Brasília: Instituto Nacional de Estudos e Pesquisas Educacionais Anísio Teixeira, 2005.

ENGUITA, M. F. O discurso da qualidade e a qualidade do discurso. In: GENTILI, P. A. A.; SILVA, T. T. Neoliberalismo, qualidade total e educação. Petrópolis, RJ: Vozes, 1994. 
FREITAS, L. C. Os reformadores empresariais da educação e a disputa pelo controle do processo pedagógico na escola. Revista Educação e Sociedade. Campinas, v. 35, n. 129, p. 1085-1114, out./dez. 2014. Disponível em <https://www.scielo.br/pdf/es/v35n129/0101-7330-es-35-12901085.pdf>, acesso em 4 de abr. de 2021.

GOMES, C. A. O tema da avaliação educacional na Constituinte de 1988 e na Lei de Diretrizes e Bases da Educação Nacional de 1996. Em Aberto, Brasília, v. 29, n. 96, p. 53-69, maio/ago. 2016. Disponível em <http://www.emaberto.inep.gov.br/ojs3/index.php/emaberto/article/view/3151>, acesso em 5 de abr. de 2021.

JOHNSON, A. G. Dicionário de Sociologia: guia prático da linguagem sociológica. tradução, Ruy Jungmann; consultoria, Renato Lessa. — Rio de Janeiro: Jorge Zahar Ed., 1997.

Ministério da Administração Federal e Reforma do Estado - MARE (1995). Plano Diretor da Reforma do Aparelho do Estado. Brasília: Imprensa Nacional, novembro 1995.

OLIVEIRA, D. A. Nova gestão pública e governos democráticos populares: contradições entre a busca da eficiência e a ampliação do direito a educação. Educação e Sociedade, Campinas, v. 36, jul./set. 2015. Disponível em: <https://www.scielo.br/pdf/es/v36n132/1678-4626-es-36-13200625.pdf>, acesso em 2 de abr. de 2021.

PANSANI, C. Pequeno Dicionário de Sociologia. Campinas, SP: Autores Associados, 2011.

SAVIANI, D.; DOURADO, L. F.; FILHO, H. A. Entrevista. Revista Retratos da Escola. Brasília, v. 8, n. 15, p. 231-246. jul./dez. 2014. Disponível em:

<http://retratosdaescola.emnuvens.com.br/rde/article/view/439>, acesso em 4 de abr. de 2021. 